\title{
A Perspective on the Recently Held World Foot and Ankle Congress
}

\author{
Mark Myerson
}

\begin{abstract}
I recognized in early April 2020 that many of the national and international academic and educational conferences had been postponed or canceled due to the impact of the world coronavirus disease-2019 (COVID-19) crisis. Our Steps2Walk humanitarian organization was forced to postpone many of our global programs in 2020, yet the ongoing need to fulfill our mission remained prescient. It was not clear when resumption of traditional meetings would take place, so I used this opportunity to develop the concept of an international Web-based meeting. This had never been attempted previously but I believed that it could take place with the resources that Steps2Walk could provide, the support of the world's foot and ankle leaders, and a strategic corporate partner. The goal of the Congress was therefore to support all surgeons during this time of crisis, recognizing the need to sustain our colleagues with a unique educational opportunity.
\end{abstract}

Keywords: COVID-19 crisis, Foot and ankle, Steps2Walk.

Journal of Foot and Ankle Surgery (Asia Pacific) (2020): 10.5005/jp-journals-10040-1130

I recognized in early April 2020 that many of the national and international academic and educational conferences had been postponed or canceled due to the impact of the world coronavirus disease-2019 (COVID-19) crisis. Our Steps2Walk humanitarian organization was forced to postpone many of our global programs in 2020, yet the ongoing need to fulfill our mission remained prescient. It was not clear when resumption of traditional meetings would take place, so I used this opportunity to develop the concept of an international Web-based meeting. This had never been attempted previously but I believed that it could take place with the resources that Steps2Walk could provide, the support of the world's foot and ankle leaders, and a strategic corporate partner. The goal of the Congress was therefore to support all surgeons during this time of crisis, recognizing the need to sustain our colleagues with a unique educational opportunity.

I began by searching for a corporate partner and found the ideal match with Paragon28, a company that is committed to worldwide education. They provided the resources that would become necessary to find the appropriate Web-based platform, IT support, pre-meeting marketing, graphic design, and post-meeting analysis. Paragon28 has made it their goal to reinvent the space of foot and ankle surgery with a constant focus on product development. They have emphasized this commitment by concentrating only on foot and ankle, with a philosophy of innovation, education, research, and humanitarian support. Paragon28's cofounder and CEO, Albert DaCosta, was exploring the same concept and this synergy allowed for an enthusiastic partnership. In order to make this a success, we had to begin thinking immediately about all of the necessary logistics (Figs 1 to 3).

I had already decided on the format for the meeting using a combination of keynote talks, didactic lectures, new ideas, and interesting surgical techniques and tips. Ensuring adequate discussion time was very difficult due to the quantity of so many excellent speakers participating. Correspondence took place initially with 123 of the world's leading thinkers in foot and ankle surgery. Of those, 118 (many of whom are colleagues and friends) replied affirmatively. Due to other obligations, we ended up with 101 speakers. Now, I had to decide how best to include each of the
Department of Orthopedic Surgery, University of Colorado School of Medicine, Steps2Walk, Baltimore, Maryland, USA

Corresponding Author: Mark Myerson, Department of Orthopedic Surgery, University of Colorado School of Medicine, Steps2Walk, Baltimore, Maryland, USA, Phone: +1 443 629-0748, e-mail: mark@ steps2walk.org

How to cite this article: Myerson M. A Perspective on the Recently Held World Foot and Ankle Congress. J Foot Ankle Surg (Asia Pacific) 2020;7(2):83-85.

Source of support: Nil

Conflict of interest: None

speakers on the program ensuring a balanced input from all the countries represented.

One of the massive obstacles that I recognized early on was the effect of the varied time zones of the world on program participation and registration. It was clear that we could not favor one continent over another, and this certainly could not be run as an American-based meeting, automatically excluding the Asian Federation. I got around this by scheduling a continuous meeting, commencing on a Friday evening in the United States. The first few speakers were American, then we moved to the Australian and Asian countries who were just beginning their Saturday morning. This evolved into a semicontinuous program over 46 hours, which would ultimately include 32 hours of live participation. This worked well in principle, but in practice would prove to be an immensely challenging aspect of the meeting planning. All time zones had to match the subject matter. This meant that presentations that may have been perfect could not be included because the agenda was subject to the time zones. There were also serious obstacles with holding the meeting as soon as possible, but this was outweighed by the opportunity to capture the audience and faculty that were currently on global quarantine. Recognizing that some countries would open their hospitals earlier than others meant that we had a very restricted time frame within which to host this program. However, I still had to get replies from the international surgeon faculty, and some of them agreed to participate while others did not

(c) The Author(s). 2020 Open Access This article is distributed under the terms of the Creative Commons Attribution 4.0 International License (https://creativecommons. org/licenses/by-nc/4.0/), which permits unrestricted use, distribution, and non-commercial reproduction in any medium, provided you give appropriate credit to the original author(s) and the source, provide a link to the Creative Commons license, and indicate if changes were made. The Creative Commons Public Domain Dedication waiver (http://creativecommons.org/publicdomain/zero/1.0/) applies to the data made available in this article, unless otherwise stated. 

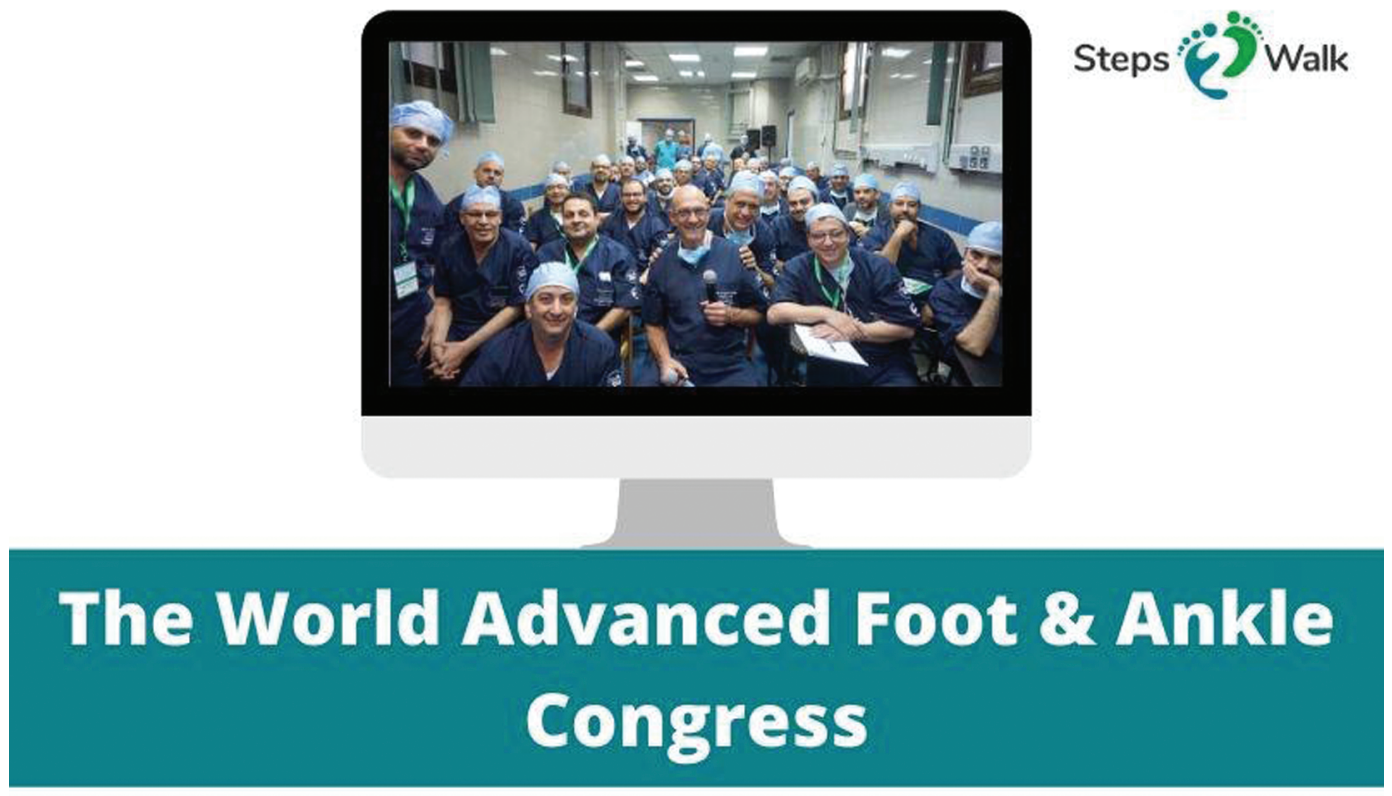

\section{A humanitarian program to bring surgeons together during the COVID19 crisis}

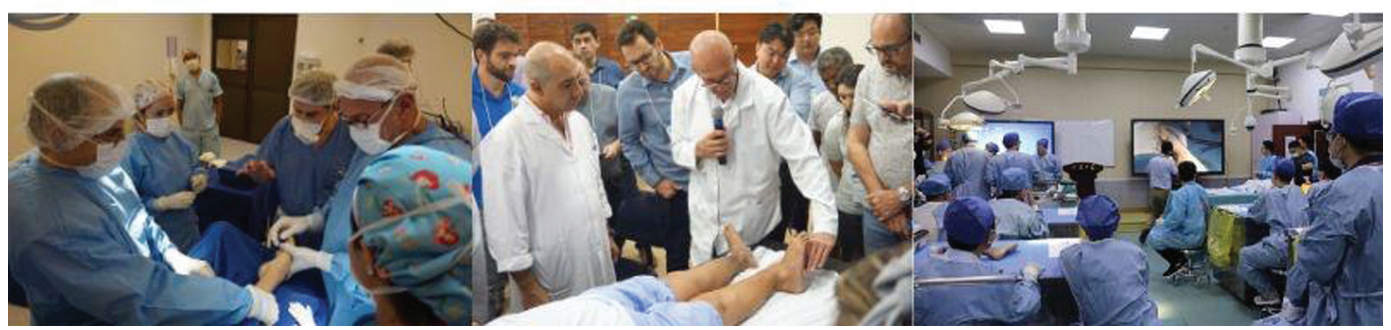

Fig. 1: The one week humanitarian program includes a day of conferences, lectures and case discussion, one day of patient examination focused on teaching, two days of live broadcasted interactive surgery, and a cadaver lab on the final day

send me their lectures to add to the meeting. Trying to organize this group of international surgeons within the tight time constraints was like trying to herd cats.

I made an error by trying to organize the talks too early in the planning process. Not only was it a matter of deciding who to put where on the program according to their time zone but also to ensure that the high quality of talks selected were comprehensive and balanced across trauma and reconstruction. Talks were submitted until very late in the process, long after I had set the deadline for submission of material and sent frequent reminders. Each time when I thought that I had the final program created, more talks suddenly would arrive and I had to rearrange the schedule repeatedly to accommodate these excellent quality presentations.

Then came the inevitable withdrawals by speakers who were suddenly called to emergency service to cover the COVID-19 crisis in their hospitals. We had already committed to a final program and while this could be changed, I thought that it would be a pity to drop those talks. The only solution was to have these talks prerecorded, which itself was not easy since they had to be prepared using a specific format and within a fixed time limit. Nonetheless, we ended up with about eight presentations prerecorded and were able to incorporate them using the sophisticated Paragon 28 IT wizardry of Nik Delaney. In further preparation for the meeting, we had daily conference calls with Paragon28 and their leadership, medical education, digital marketing, graphic design, and IT teams. These meetings became more frequent as we approached the opening ceremony. I and $\mathrm{Dr}$ Shuyuan Li, the program coordinator, had been working for 14-16 hours a day for 3 very stressful weeks. With the IT team and other Paragon28 members, we performed a few trial runs during the preceding week to iron out technical aspects of the program, which uncovered many unanticipated issues. We also offered a trial run for each of the speakers to ensure that they could login easily and their computers were functioning. Fortunately, this exposed a problem with MAC computers, which was corrected ahead of time on each device.

Arjun Padmakumar, director of social media for Steps2Walk, and the Paragon28 team spent the final few days fine-tuning everything 


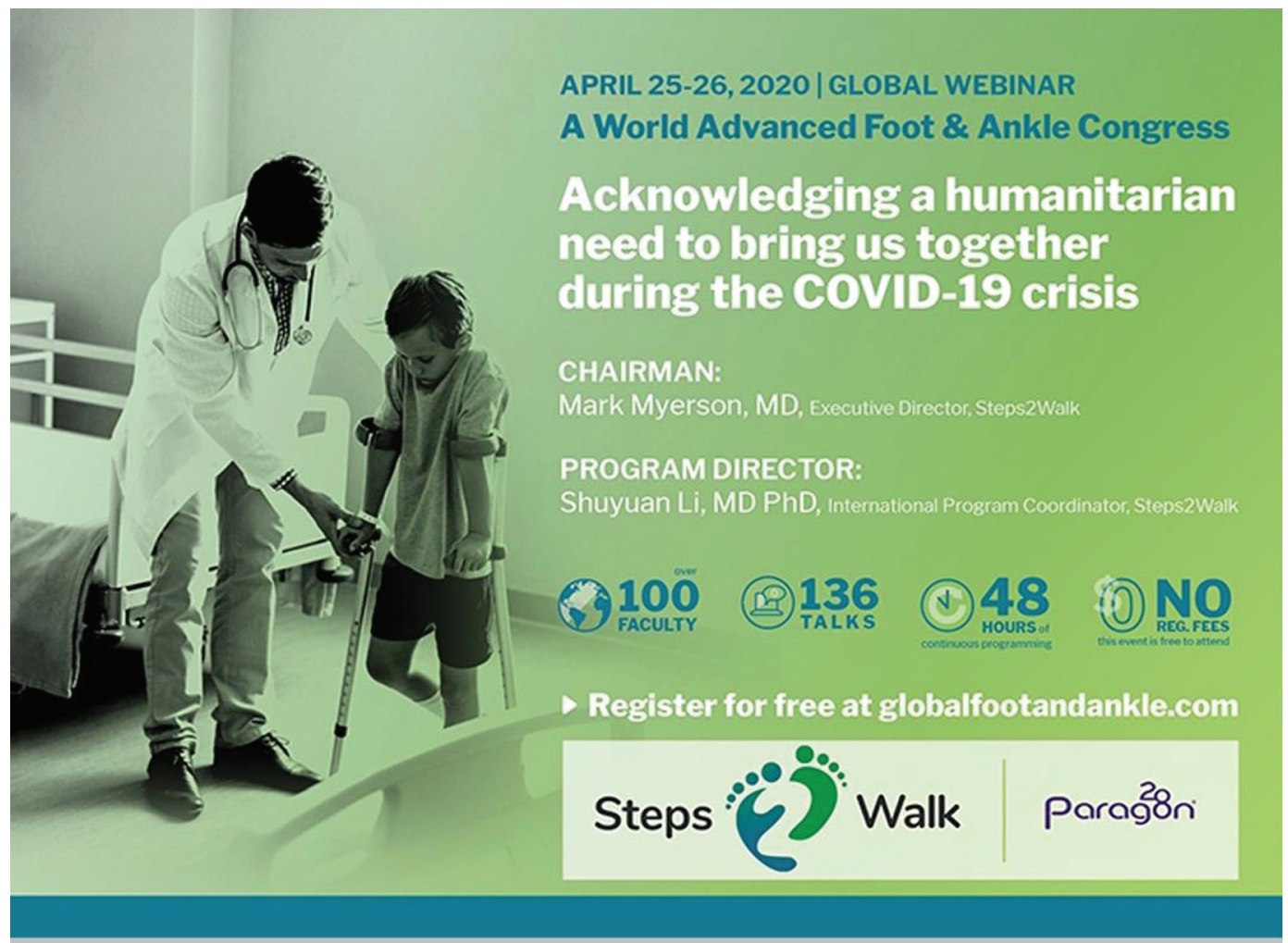

Fig. 2: The meeting announcements were used to stream constantly during the program
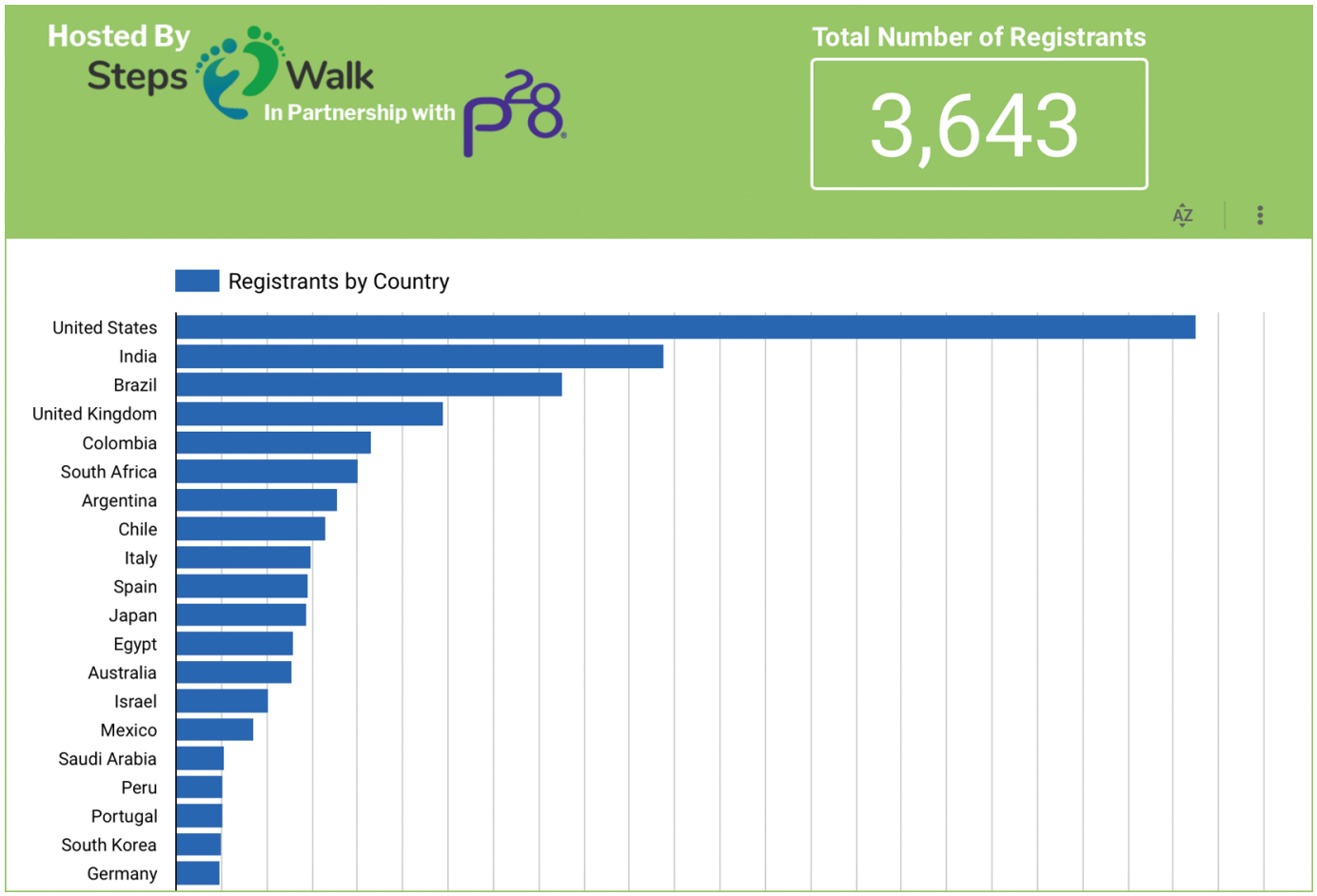

Fig. 3: There were almost 8,000 surgeons from 38 countries registered for the World Congress

and making sure the social media presence was on point. Our weeks of preparation culminated in the final moment when I delivered the keynote address in the opening ceremony to an audience of over 6,000 registrants from every region of the world.
This was a good learning experience. All of us at Steps2Walk, the experts at Paragon28, and the distinguished faculty continue to share the pride of this very successful endeavor! 